\title{
Enhancement of the dissolution rate and bioavailability of fenofibrate by a melt-adsorption method using supercritical carbon dioxide
}

This article was published in the following Dove Press journal:

International Journal of Nanomedicine

24 October 2012

Number of times this article has been viewed

\section{Kwang-Ho Cha ${ }^{1,3}$ \\ Kyung-Jin $\mathrm{Cho}^{3}$ \\ Min-Soo $\mathrm{Kim}^{4}$ \\ Jeong-Soo $\mathrm{Kim}^{3}$ \\ Hee Jun Park ${ }^{1,3}$ \\ Junsung Park ${ }^{1,3}$ \\ Wonkyung Cho',3 \\ Jeong-Sook Park ${ }^{3}$ \\ Sung-Joo Hwang ${ }^{1,2}$}

'Yonsei Institute of Pharmaceutical Sciences, ${ }^{2}$ College of Pharmacy, Yonsei University, Incheon, Republic of Korea; ${ }^{3}$ College of Pharmacy, Chungnam National University, Daejeon, Republic of Korea; ${ }^{4}$ Department of Pharmaceutical Engineering, Inje University, Gimhae, Republic of Korea

Correspondence: Sung-Joo Hwang College of Pharmacy, Yonsei

University, I62-I Songdo-dong,

Yeonsu-gu, Incheon 406-840,

Republic of Korea

Tel +82 3274945 I 8

Fax +82327494105

Email sjh I I@yonsei.ac.kr

Jeong-Sook Park

College of Pharmacy, Chungnam National University, Daejeon, Republic of Korea

$\mathrm{Tel}+82428215932$

Fax +82428236566

Email eicosa@cnu.ac.kr
Background: The aim of this study was to enhance the bioavailability of fenofibrate, a poorly water-soluble drug, using a melt-adsorption method with supercritical $\mathrm{CO}_{2}$.

Methods: Fenofibrate was loaded onto Neusilin ${ }^{\circledR}$ UFL2 at different weight ratios of fenofibrate to Neusilin UFL2 by melt-adsorption using supercritical $\mathrm{CO}_{2}$. For comparison, fenofibrateloaded Neusilin UFL2 was prepared by solvent evaporation and hot melt-adsorption methods. The fenofibrate formulations prepared were characterized by differential scanning calorimetry, powder x-ray diffractometry, specific surface area, pore size distribution, scanning electron microscopy, and energy-dispersive x-ray spectrometry. In vitro dissolution and in vivo bioavailability were also investigated.

Results: Fenofibrate was distributed into the pores of Neusilin UFL2 and showed reduced crystal formation following adsorption. Supercritical $\mathrm{CO}_{2}$ facilitated the introduction of fenofibrate into the pores of Neusilin UFL2. Compared with raw fenofibrate, fenofibrate from the prepared powders showed a significantly increased dissolution rate and better bioavailability. In particular, the area under the drug concentration-time curve and maximal serum concentration of the powders prepared using supercritical $\mathrm{CO}_{2}$ were 4.62-fold and 4.52-fold greater than the corresponding values for raw fenofibrate.

Conclusion: The results of this study highlight the usefulness of the melt-adsorption method using supercritical $\mathrm{CO}_{2}$ for improving the bioavailability of fenofibrate.

Keywords: fenofibrate, melt adsorption, supercritical $\mathrm{CO}_{2}$, bioavailability

\section{Introduction}

Fenofibrate is the isopropyl ester of 2-(4-[4-chloro-benzoyl] phenoxy)-2methylpropanoic acid and has been used for many years to reduce cholesterol and triglyceride concentrations in plasma. ${ }^{1}$ Fenofibrate is marketed in many countries, and its pharmacological activity and pharmacokinetic profile are well understood. ${ }^{2}$ The compound is practically insoluble in water and has high lipophilicity $(\log P=5.24)$. According to the Biopharmaceutics Classification System, fenofibrate is a class II drug with low solubility and high permeability. Thus, the dissolution rate of fenofibrate may limit its absorption in the gastrointestinal tract.

The dissolution rate of a drug can be improved by a variety of techniques. Particle size reduction or amorphization of a drug promotes rapid dissolution and effective absorption in the body. ${ }^{3-5}$ Several studies have been carried out to investigate methods for increasing the dissolution rate of drugs by decreasing particle size (eg, by developing nanoparticles and microparticles). ${ }^{6,7}$ However, handling micronized drugs is often problematic because extremely small particles tend to agglomerate, requiring additional stabilization. 
A method for improving the dissolution rate, while avoiding these difficulties, involves adsorption of drugs onto a mesoporous carrier. With this technique, the drug is dissolved in an organic solvent, and the resulting solution is used to soak a mesoporous carrier such as silica. ${ }^{8-10}$ Agglomeration of drug particles is prevented by binding of the drug to the carrier. However, because of the presence of residual solvent in the drug formulation, it is disadvantageous to use toxic solvents. To overcome this problem, supercritical $\mathrm{CO}_{2}$ technology was used in this study.

Supercritical $\mathrm{CO}_{2}$ is the most widely used supercritical fluid because of its mild critical conditions, nontoxicity, nonflammability, and low cost. ${ }^{11}$ Supercritical fluid techniques have frequently been used to modify the solid-state properties of active pharmaceutical ingredients, such as polymorphism and crystallinity, that affect their dissolution rate and bioavailability. ${ }^{12,13}$ Sanganwar et al used supercritical $\mathrm{CO}_{2}$ as the solvent for adsorption of fenofibrate onto silica for enhancement of the dissolution rate. ${ }^{14}$ They found that the dissolution rate increased significantly; however, the drug-loading capacity was approximately 25-27 wt \% because of the relatively low solubility of fenofibrate in supercritical $\mathrm{CO}_{2}$.

In this study, supercritical $\mathrm{CO}_{2}$ was used to lower both the melting temperature of fenofibrate and the viscosity of molten fenofibrate. Fischer et al reported that gases with high solubility (eg, carbon dioxide, ethylene, and xenon) can decrease melting points considerably, whereas those with low solubility (eg, helium and nitrogen) increase melting points. ${ }^{15}$ For this reason, the melting point of fenofibrate is decreased in supercritical $\mathrm{CO}_{2}$. The melted fenofibrate can then be dispersed in supercritical $\mathrm{CO}_{2}$ and distributed into the pores of mesoporous silica. This process works on the basis that pressurized gas can diffuse into a solute, lowering both its melting point and viscosity. Therefore, because this process does not affect the solubility of a drug in supercritical fluid, it is possible to prepare a dose with increased drug loading.

Neusilin ${ }^{\circledR}$ UFL2 (Fuji Chemical Industry Co., Ltd, Toyama, Japan) is a fine amorphous powder of magnesium aluminometasilicate, has the structure of a secondary agglomeration particle, is approximately $5 \mu \mathrm{m}$ in diameter, and has high porosity. It has a very large specific surface area, high oil adsorption and absorption capacities, and excellent dispersibility. ${ }^{16}$ Neusilin UFL2 is also less likely to promote reversion of the amorphous drug to the crystalline state with storage of the solid dispersion, because of its amorphous nature. ${ }^{17}$ Therefore, Neusilin UFL2 can be used to increase surface area and amorphization of a drug.
In the present study, fenofibrate formulations adsorbed onto pores of Neusilin UFL2 were prepared using supercritical $\mathrm{CO}_{2}$. The specific surface area, total pore volume, crystallinity, scanning electron microscopy (SEM), energydispersive spectrometry (EDS), in vitro dissolution, and in vivo bioavailability of fenofibrate were examined.

\section{Materials and methods Materials}

Fenofibrate and clofibrate were purchased from SigmaAldrich (St Louis, MO). Neusilin UFL2 was obtained as a gift from Fuji Chemical Industry Co, Ltd (Toyama, Japan). Sodium lauryl sulfate was purchased from Duksan Pure Chemicals Co, Ltd (Ansan-si, Korea). High-purity $\mathrm{CO}_{2}$ (99.99\%) was supplied from Han-Mi Gas Co, Ltd (Korea). Acetonitrile and tetrahydrofuran were of high-performance liquid chromatography (HPLC) grade. All other reagents were of analytical reagent grade, and double-distilled water was used throughout the study. Commercial fenofibrate was purchased as Lipidil Supra ${ }^{\circledR}$ (Green Cross Co, Ltd, Seoul, Korea).

\section{Determination of melting-point depression}

To determine the melting point, a high-pressure variable volume view cell with a single sapphire window was used. The phase behavior within the cell was monitored through the window by video camera. Pressure was controlled by moving the piston used to change the cell volume at constant temperature. The temperature was fixed by a watercirculating jacket surrounding the cell and an air convection oven. This apparatus is schematized in Figure 1.

To measure the melting point in a binary system of fenofibrate and $\mathrm{CO}_{2}$, the fenofibrate was loaded inside a glass tube (internal diameter $1.2 \mathrm{~mm}$ ) that served as a sample carrier. The cell was sealed following insertion of the glass tube containing pure fenofibrate. Air was removed from the cell by sequential injections of $\mathrm{CO}_{2}$. Supercritical $\mathrm{CO}_{2}$ was added to the cell using a syringe pump at a relatively low initial pressure. Following initial stabilization of both pressure and temperature, the pressure was subsequently increased in small increments ( 5 bar) by moving the piston and maintained for at least 15 minutes to reach phase equilibrium. Depression of the melting point of fenofibrate was determined by visual observation when the first droplet of the liquid was formed inside the system. ${ }^{18}$ 


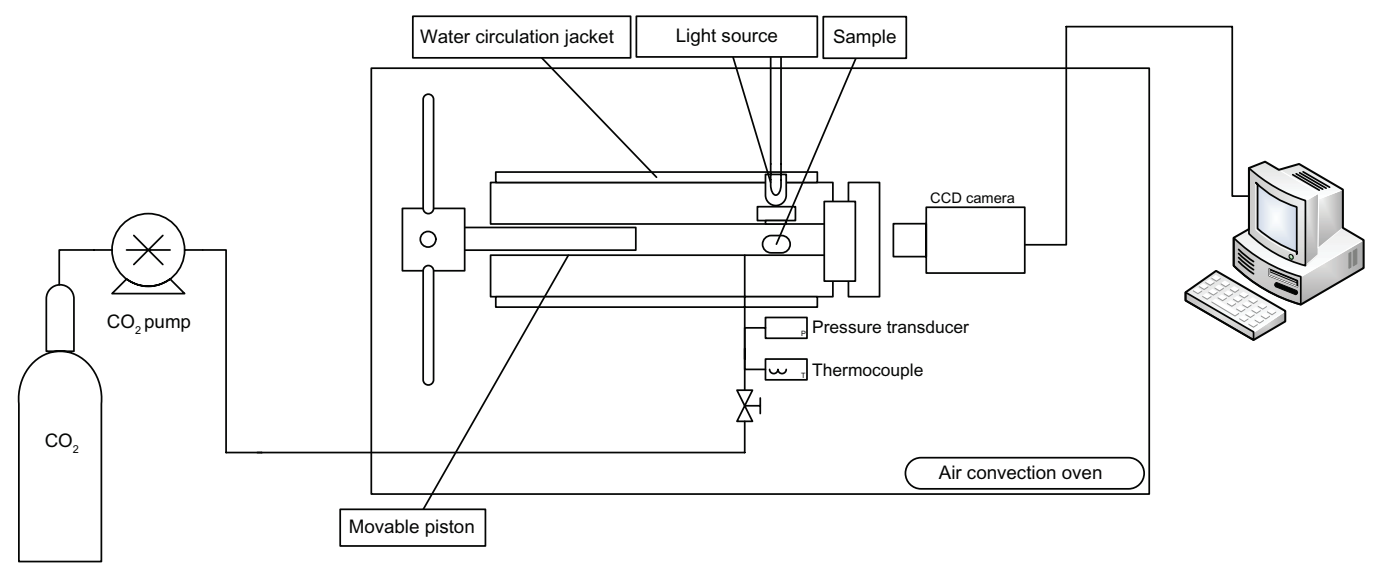

Figure I Experimental apparatus for phase-behavior observations.

\section{Drug loading}

\section{Supercritical method}

Figure 2 shows a schematic of the experimental setup used for adsorption of fenofibrate onto Neusilin UFL2. A fixed amount of fenofibrate ( $10 \mathrm{~g})$ was mixed with specific quantities of Neusilin UFL2 and the mixture was placed into a $600 \mathrm{~mL}$ stainless pressure vessel containing a stirrer. The mass ratio of fenofibrate to Neusilin UFL2 is shown in Table 1. After sealing the pressure vessel, supercritical $\mathrm{CO}_{2}$ was pumped inside until the desired pressure was achieved. The temperature of the pressure vessel was then maintained using a heat circulator. The rotation speed was fixed at $50 \mathrm{rpm}$ to equilibrate the contents for one hour. The rotation speed was then accelerated to $100 \mathrm{rpm}$ for one hour at constant pressure and temperature to adsorb a melted mixture onto the Neusilin UFL2 pores. In this step, supercritical $\mathrm{CO}_{2}$ aids homogeneous adsorption by acting as a dispersive medium. After being mixed well, the vessel was depressurized for approximately one hour at constant temperature and a constant stirring speed $(100 \mathrm{rpm})$ to remove the $\mathrm{CO}_{2}$. The vented $\mathrm{CO}_{2}$ was passed through the water in the trap, and the prepared powders were collected at the bottom of the pressure vessel.

\section{Solvent evaporation method}

Fenofibrate $400 \mathrm{mg}$ was dissolved in $40 \mathrm{~mL}$ of ethanol, and Neusilin UFL2 $600 \mathrm{mg}$ was then added to the fenofibrate solution. The suspension was brought to equilibrium while stirring for 12 hours, after which ethanol was evaporated through a rotary evaporator at $50^{\circ} \mathrm{C}$.

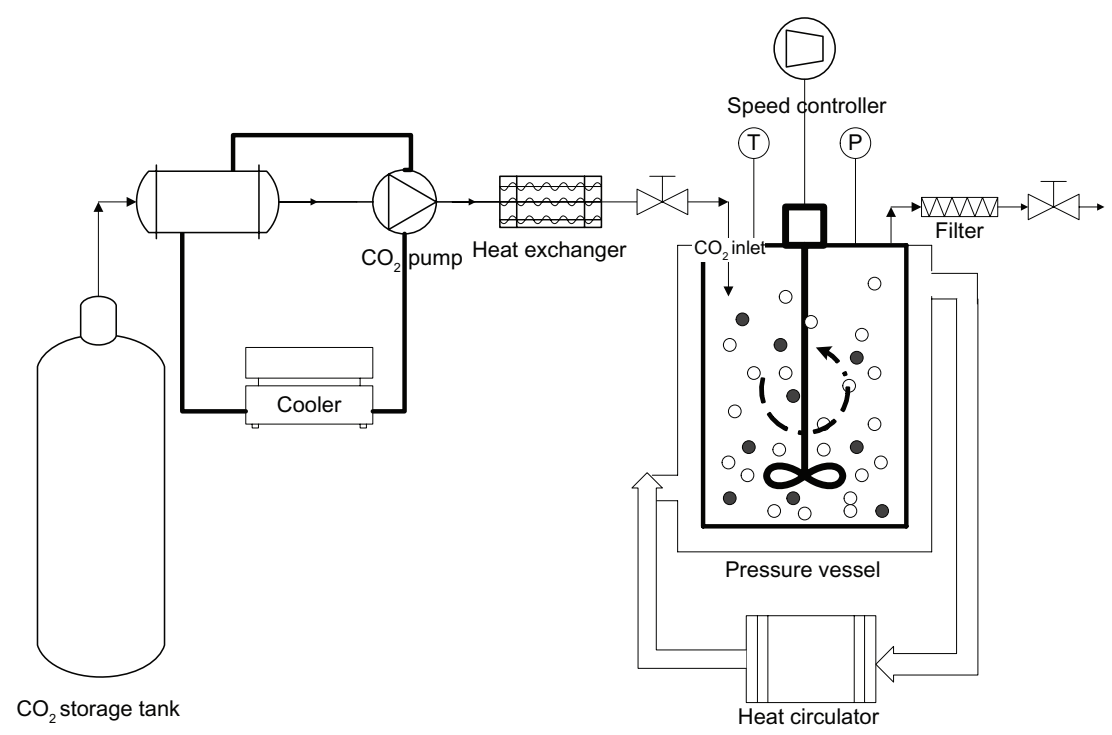

Figure 2 Schematic diagram of the experimental apparatus. 
Table I Composition of prepared powders containing fenofibrate and Neusilin ${ }^{\circledR}$ UFL2 in different ratios

\begin{tabular}{|c|c|c|c|c|}
\hline \multirow[t]{2}{*}{ Formulation } & \multicolumn{2}{|l|}{$\begin{array}{l}\text { Experimental } \\
\text { parameter }\end{array}$} & \multicolumn{2}{|c|}{$\begin{array}{l}\text { Ratio of } \\
\text { ingredients (\%) }\end{array}$} \\
\hline & $\begin{array}{l}\text { Temperature } \\
\text { (K) }\end{array}$ & $\begin{array}{l}\text { Pressure } \\
(\mathrm{MPa})\end{array}$ & Fenofibrate & $\begin{array}{l}\text { Neusilin } \\
\text { UFL2 }\end{array}$ \\
\hline \multicolumn{5}{|c|}{ Supercritical method } \\
\hline $\mathrm{SCl}$ & 323.15 & 9 & 67 & 33 \\
\hline SC2 & 323.15 & 9 & 50 & 50 \\
\hline SC3 & 323.15 & 9 & 40 & 60 \\
\hline SC4 & 323.15 & 9 & 33 & 67 \\
\hline $\begin{array}{l}\text { Solvent } \\
\text { evaporation } \\
\text { method }\end{array}$ & - & - & 40 & 60 \\
\hline $\begin{array}{l}\text { Hot-melt } \\
\text { adsorption } \\
\text { method }\end{array}$ & - & - & 40 & 60 \\
\hline
\end{tabular}

Abbreviations: $\mathrm{SCl}$, supercritical method I (fenofibrate:Neusilin UFL2 = 67:33); SC2, supercritical method 2 (fenofibrate:Neusilin UFL2 $=50: 50$ ); SC3, supercritical method 3 (fenofibrate:Neusilin UFL2 = 40:60); SC4, supercritical method 4 (fenofibrate:Neusilin UFL2 = 33:67).

\section{Hot-melt adsorption method}

Fenofibrate $400 \mathrm{mg}$ was fully mixed with Neusilin UFL2 $600 \mathrm{mg}$. The mixture was heated to above $90^{\circ} \mathrm{C}$ to melt the fenofibrate, which was then allowed to cool to room temperature.

\section{Specific surface area and pore size distribution}

The specific surface area and pore size distribution of the powder prepared was determined using a surface area and pore size analyzer (ASAP 2010; Micromeritics, Norcross, GA). Surface area calculations were made based on the BrunauerEmmett-Teller equation using the software provided. The pore size distribution was calculated from the desorption isotherm using the Barrett-Joyner-Halenda model.

\section{Differential scanning calorimetry}

Differential scanning calorimetry was carried out using a DSC S-650 (Scinco Co, Ltd, Seoul, Korea). All samples (2-4 mg) were accurately weighed using a microbalance and sealed in aluminum pans. Measurements were performed with a heating rate of $10^{\circ} \mathrm{C}$ per minute covering a temperature range of $25^{\circ} \mathrm{C}-120^{\circ} \mathrm{C}$, and a nitrogen gas flow rate of $40 \mathrm{~mL}$ per minute. An empty sealed pan was used as the reference sample. The amount of crystalline fenofibrate in the samples was estimated from the area under the fenofibrate melting peak for the sample compared with that for the raw fenofibrate as follows: ${ }^{19}$

$$
\mathrm{AC}(\%)=\frac{\mathrm{C}_{\text {sample }}}{\mathrm{C}_{\text {raw }}} \times 100,
$$

where $\mathrm{AC}$ is the amount of crystalline fenofibrate in the sample, $\mathrm{C}_{\text {sample }}$ is the area under the fenofibrate melting peak for the sample, and $\mathrm{C}_{\text {raw }}$ is the area under the melting peak for the raw fenofibrate. The melting peaks were integrated using the software provided. Because the area under the melting peak of the sample depends on the amount sampled, the area was normalized by the sample size.

\section{Powder X-ray diffraction (PXRD)}

The PXRD patterns of the samples were recorded on a powder X-ray diffractometer (D/Max-2200 Ultima/PC; Rigaku, The Woodlands, TX) with a Ni-filtered $\mathrm{Cu}-\mathrm{K} \alpha$ line as the source of radiation. The $2 \theta$ scan range was $10^{\circ}-80^{\circ}$ with a step size of $0.05^{\circ}$, and the scan speed was $5^{\circ}$ per minute.

\section{Scanning electron microscopy (SEM) and energy dispersive spectrometry (EDS)} SEM (JSM-7000F; JEOL, Tokyo, Japan) was used for the morphological analysis. EDS (INCA X-act; Oxford Instruments, Abingdon, UK) was used to analyze elements on the surface of the raw fenofibrate, Neusilin UFL2, and the prepared powders. Samples were first distributed evenly on conductive carbon adhesive tape and then coated with a thin layer of gold.

\section{In vitro dissolution studies}

A dissolution study was carried out using USP II apparatus (VK7000; Vankel, Cary, NC). Samples containing the equivalent of $160 \mathrm{mg}$ of fenofibrate were placed into $900 \mathrm{~mL}$ of $0.025 \mathrm{M}$ sodium lauryl sulfate at $37^{\circ} \mathrm{C} \pm 0.1^{\circ} \mathrm{C}$ and stirred at $75 \mathrm{rpm}$. At predetermined time points, $2 \mathrm{~mL}$ of each sample was drawn and filtered using a $0.45 \mu \mathrm{m}$ polytetrafluoroethylene syringe filter. Filtered samples were appropriately diluted with the dissolution medium, and the amount of dissolved drug was determined by HPLC. The HPLC system consisted of a Waters 2690 Alliance analytical column including an autosampler and a Waters 996 photodiode-array ultraviolet detector (Waters, Milford, MA). The analytical column was an Xterra RP-18 $5 \mu \mathrm{m}(4.6 \times 50 \mathrm{~mm}, 5 \mu \mathrm{m}$; Waters $)$. The mobile phase consisted of $30 \% 0.02 \mathrm{M}$ phosphoric acid solution and $70 \%$ acetonitrile at a flow rate of $1 \mathrm{~mL}$ per minute. The ultraviolet detection wavelength was $286 \mathrm{~nm}$. Data acquisition and evaluation were performed using Millennium 32 software (Waters). 


\section{Pharmacokinetic study in rats}

All animal experiments were carried out according to the guidelines for the care and use of laboratory animals at Chungnam National University. Male Sprague Dawley rats (6-7 weeks old) weighing 180-200 g were used for the study. The animals were housed in a cage at room temperature $\left(25^{\circ} \mathrm{C}\right)$ and relative humidity of $55 \% \pm 10 \%$, with 12-hour light/dark cycles. The animals had free access to water and a pelleted diet, and were fasted 24 hours prior to the experiment. The rats were divided into six groups of five animals each. Each group was orally administered $1 \mathrm{~mL}$ of $0.2 \% \mathrm{w} / \mathrm{v}$ methylcellulose aqueous suspension containing the raw fenofibrate, the commercial product (Lipidil Supra), or the prepared powders (equivalent to fenofibrate $50 \mathrm{mg} / \mathrm{kg}$ bodyweight), respectively. Blood samples were collected from the tail vein prior to the initial dose, and then at 20 , $40,60,90,120,180,240,360,480$, and 720 minutes after dosing. Blood samples were centrifuged at 10,000 rpm and the separated serum samples were transferred into individual Eppendorf tubes at $-20^{\circ} \mathrm{C}$ prior to analysis.

\section{Determination of serum fenofibrate concentration}

A $100 \mu \mathrm{L}$ serum sample was spiked with $10 \mu \mathrm{L}$ of an internal standard solution (clofibrate, $2000 \mu \mathrm{g} / \mathrm{mL}$ ), followed by addition of $100 \mu \mathrm{L}$ of $1 \mathrm{M} \mathrm{HCl}$. After vortex mixing for $30 \mathrm{sec}-$ onds, $500 \mu \mathrm{L}$ of $n$-hexane/ethyl acetate $(9: 1 \mathrm{v} / \mathrm{v})$ solution was added, and the resulting solution was mixed vigorously for 5 minutes. The mixed serum sample was centrifuged for 10 minutes at 13,000 rpm. The clear supernatants were transferred to an Eppendorf tube and evaporated under a gentle stream of nitrogen at $40^{\circ} \mathrm{C}$. The residue was reconstituted in $1 \mathrm{~mL}$ of a mixture of distilled water and acetonitrile $(7: 3)$ and centrifuged at $3000 \mathrm{rpm}$ for 5 minutes. An aliquot of $50 \mu \mathrm{L}$ of supernatant solution was injected into the HPLC system.

Fenofibric acid and clofibric acid levels in rat serum were determined by HPLC. The analytical column was an Xterra RP-18 $5 \mu \mathrm{m}(4.6 \times 50 \mathrm{~mm}, 5 \mu \mathrm{m}$; Waters). The mobile phase was composed of a mixture of a $0.02 \mathrm{M}$ phosphate-buffered solution and acetonitrile $(55: 45, \mathrm{v} / \mathrm{v}), \mathrm{pH}$ 3.4. The flow rate was $1.2 \mathrm{~mL}$ per minute. Ultraviolet detection was set at a wavelength of $286 \mathrm{~nm}$.

\section{Pharmacokinetic data analysis}

The time to reach the maximum serum concentration and the maximal serum concentration of the drug $\left(\mathrm{C}_{\max }\right)$ were obtained directly from the concentration-time curve. The area under the drug concentration-time curve (AUC) was calculated using WinNonlin 2.1 (Pharsight Corporation, Mountain View, CA). A one-way analysis of variance test was used for statistical evaluation using SPSS 12.0 software (SPSS Inc, Chicago, IL).

\section{Results and discussion Phase behavior study}

To determine the operating conditions of the supercritical method, a phase behavior study including melting point depression and solubility studies was conducted. Experimentally measured values of the melting temperature for raw fenofibrate in the presence of compressed $\mathrm{CO}_{2}$ are shown in Figure 3. It was observed that the melting point of fenofibrate decreased significantly with increasing pressure, ranging from $0.1 \mathrm{MPa}$ to $8 \mathrm{MPa}$. These results are consistent with those of a previous study demonstrating that the melting point of solid substances can be significantly reduced by using supercritical fluids that are highly soluble in the molten substance. ${ }^{20}$ The $\mathrm{CO}_{2}$ gas used in this experiment was significantly soluble in molten fenofibrate under high pressure, ${ }^{21,22}$ leading to the decreased melting point of fenofibrate observed in this study.

For the solubility study, the solubility of fenofibrate in supercritical $\mathrm{CO}_{2}$ was calculated from the following equation:

$$
\begin{aligned}
T(\mathrm{~K}) \ln (y \mathrm{P}(\mathrm{MPa}))= & -9410.5+3.5386 \rho_{1}\left(\mathrm{~kg} / \mathrm{m}^{3}\right) \\
& +18.337 T(\mathrm{~K})
\end{aligned}
$$

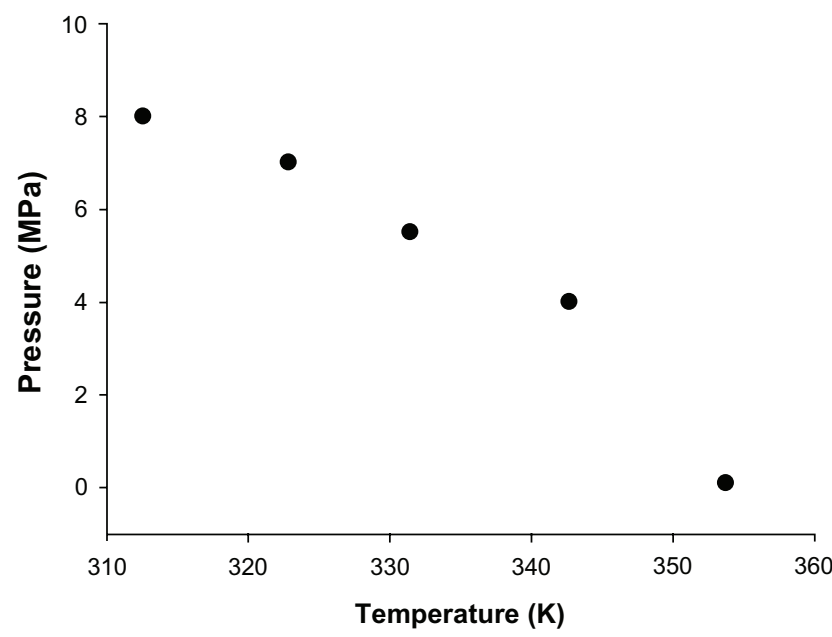

Figure 3 Solid-liquid-vapor curves for the binary system of fenofibrate + carbon dioxide. 
where $y$ is the equilibrium solid solubility (mole fraction) of solid fenofibrate in supercritical $\mathrm{CO}_{2}$ and $\rho_{1}$ is the density of supercritical $\mathrm{CO}_{2}$.

This equation comes from Chen et al, who studied the solid solubility of fenofibrate in supercritical $\mathrm{CO}_{2}$. They measured the solid solubility of fenofibrate in supercritical $\mathrm{CO}_{2}$ using a semiflow apparatus and fitted the measured data into the semiempirical model of Mendez-Santiago and Teja. ${ }^{23}$ As shown in Table 2, the solubility of fenofibrate increases with increasing pressure, but decreases with increasing temperature. With increasing solubility, the fenofibrate dissolved in supercritical $\mathrm{CO}_{2}$ can be drained from the pores of Neusilin UFL2 during the depressurizing step. Consequently, the loading of fenofibrate onto Neusilin UFL2 using the supercritical method was conducted at $323.15 \mathrm{~K}$ and $9 \mathrm{MPa}$, which shows the lowest solubility of fenofibrate in supercritical $\mathrm{CO}_{2}$. At this operating condition, fenofibrate was successfully adsorbed onto Neusilin UFL2, and both process yield and drug content exceeded $99 \%$ in all formulations (data not shown). This result is attributable to the decreased drug loss during this operating process in which only $73 \mathrm{mg}$ of fenofibrate was dissolved in supercritical $\mathrm{CO}_{2}$ (the amount of $\mathrm{CO}_{2}$ used for achieving $9 \mathrm{MPa}$ at $323.15 \mathrm{~K}$ was $171 \mathrm{~g}$ ). Furthermore, no chemical degradation was observed, as confirmed by HPLC.

\section{Crystallinity evaluation}

The differential scanning calorimetry thermograms and PXRD patterns for fenofibrate and powders prepared with various fenofibrate to Neusilin UFL2 ratios can be seen in Figure 4. Fenofibrate was characterized by a single sharp melting endothermic peak at $81.5^{\circ} \mathrm{C}(\Delta \mathrm{H}=80.57 \mathrm{~J} / \mathrm{g})$ during differential scanning calorimetry analysis, and various diffraction peaks due to the fenofibrate crystalline (form I) structure were observed at $12^{\circ}, 14.5^{\circ}, 16.2^{\circ}, 16.8^{\circ}$, and $22.4^{\circ}$ in the PXRD analysis, which corresponds to the known melting endothermic peak and powder diffraction patterns for

Table 2 Results calculated from the Mendez-Santiago and Teja model for solubility of fenofibrate in supercritical $\mathrm{CO}_{2}$

\begin{tabular}{lll}
\hline $\mathbf{T}(\mathbf{K})$ & $\mathbf{P}(\mathbf{M P a})$ & Solubility $(\mathbf{m g} / \mathbf{g})$ \\
\hline 313.15 & 9 & 1.79 \\
& 11 & 13.80 \\
323.15 & 13 & 22.92 \\
& 9 & 0.43 \\
& 11 & 3.80 \\
& 13 & 13.87 \\
\hline
\end{tabular}

Abbreviations: $\mathrm{T}$, temperature; $\mathrm{P}$, pressure.

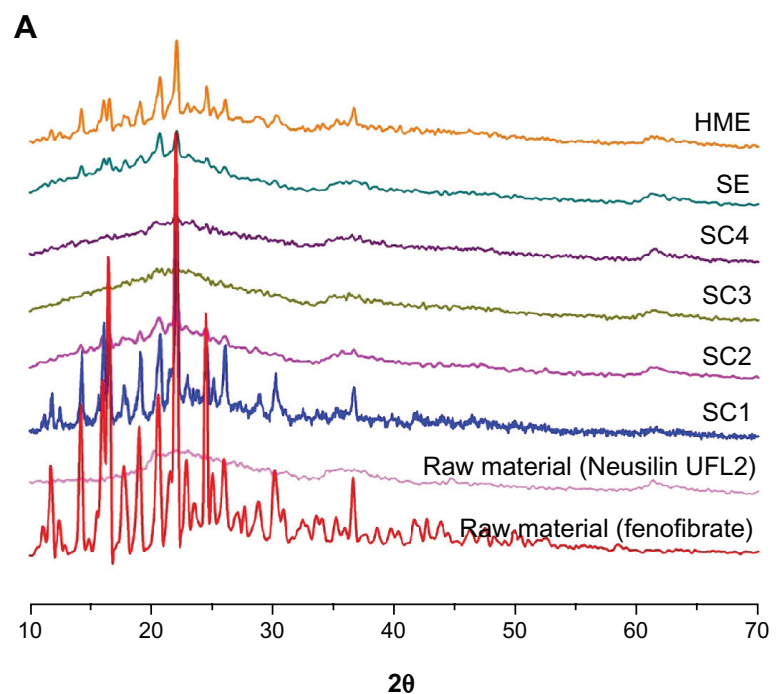

B

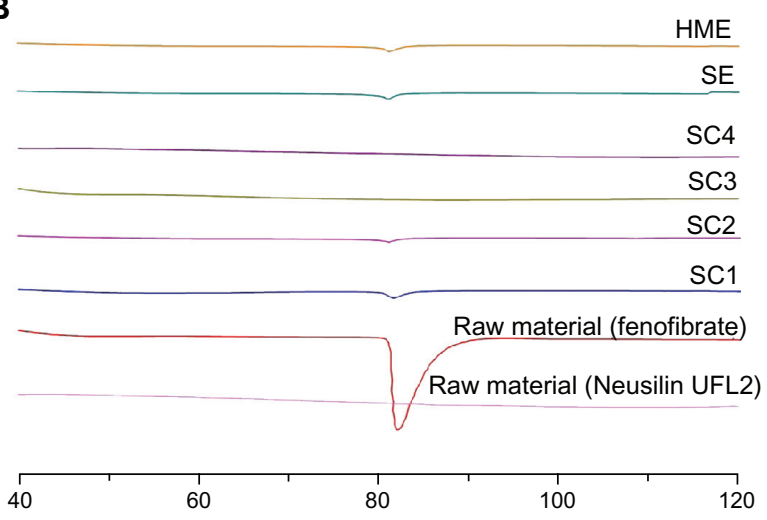

Figure 4 Powder $\mathrm{X}$-ray diffraction patterns (A) and differential scanning calorimetry thermograms (B) of raw fenofibrate and prepared powders.

Abbreviations: HME, hot-melt adsorption method; SE, solvent evaporation method; SCI, supercritical method I (fenofibrate:Neusilin UFL2 = 67:33); SC2, supercritical method 2 (fenofibrate:Neusilin UFL2 = 50:50); SC3, supercritical method 3 (fenofibrate:Neusilin UFL2 = 40:60); SC4, supercritical method 4 (fenofibrate:Neusilin UFL2 = 33:67).

pure fenofibrate. ${ }^{24,25}$ In the case of Neusilin UFL2, neither an endothermic peak of differential scanning calorimetry nor diffraction peaks from PXRD patterns were observed because of its amorphous structure. Table 3 and Figure 4 illustrate decreasing crystallinity corresponding to an increasing Neusilin UFL2 ratio and the change to the amorphous form in the case of SC3 and SC4.

For crystallization processes in confined spaces, it is known that the diameter of pores should be 20 times larger than the molecular size. ${ }^{26}$ To calculate the molecular size of fenofibrate, molecular modeling was carried out using ChemBio 3D Ultra version 12.0 (CambridgeSoft, Cambridge, MA) following energy minimization with MM2 (Figure 5). From this model, the sizes of the fenofibrate molecules were estimated to be in the range of $0.98-1.27 \mathrm{~nm}$. The pore diameter of Neusilin UFL2 was approximately $17 \mathrm{~nm}$, which is about 
Table 3 Physicochemical characterization of raw fenofibrate, Neusilin ${ }^{\circledR}$ UFL2, and the prepared powders

\begin{tabular}{llll}
\hline Formulation & Total pore volume $\left(\mathbf{c m}^{3} / \mathbf{g}\right)$ & Specific surface area $\left(\mathbf{m}^{2} / \mathbf{g}\right)$ & AC $(\%)$ \\
\hline Fenofibrate raw material & - & - & 100 \\
Neusilin UFL2 raw material & 1.476 & 403.93 & - \\
SCI & 0.190 & 31.35 & $32.16 \pm 3.91$ \\
SC2 & 0.397 & 60.95 & $1.83 \pm 0.35$ \\
SC3 & 0.486 & 72.11 & 0.00 \\
SC4 & 0.668 & 110.75 & 0.00 \\
Solvent evaporation method & 0.521 & 81.91 & $4.21 \pm 1.09$ \\
Hot-melt adsorption method & 0.589 & 92.54 & $9.43 \pm 2.11$ \\
\hline
\end{tabular}

Notes: $A C, A C(\%)=C_{\text {sample }} / C_{\text {raw }} \times 100$ where $A C$ is the amount of crystalline drug in the sample, $C_{\text {sample }}$ is the area under the fenofibrate melting peak for the sample, and $\mathrm{C}_{\text {raw }}$ is the area under the melting peak for the raw fenofibrate.

Abbreviations: SCI, supercritical method I (Fenofibrate:Neusilin UFL2 = 67:33); SC2, supercritical method 2 (Fenofibrate:Neusilin UFL2=50:50); SC3, supercritical method 3 (Fenofibrate:Neusilin UFL2 = 40:60); SC4, supercritical method 4 (Fenofibrate:Neusilin UFL2 = 33:67).

13-17 times larger than that of the fenofibrate molecule. Therefore, the restricted pore size of Neusilin UFL2 inhibited the crystalline formation of fenofibrate.

When the fenofibrate to Neusilin UFL2 ratio exceeded 50:50, both the endothermic peak of differential scanning calorimetry and the diffraction peaks of the PXRD patterns were detected. Above this ratio, the pore volume of Neusilin UFL2 was insufficient for hosting the extra fenofibrate molecule, and the residual fenofibrate would instead reside on the external surface of Neusilin UFL2.

Figure 6 shows the PXRD patterns of SC3 and SC4 after one month of storage under stress conditions of $40^{\circ} \mathrm{C}$ and $75 \%$ relative humidity. No PXRD patterns could be detected, indicating that no crystal growth occurred during storage. This tendency was also reported by Shen et al who studied the adsorption of ibuprofen onto submicron mesoporous SBA-15 particles..$^{27}$ They reported that the uniform silica

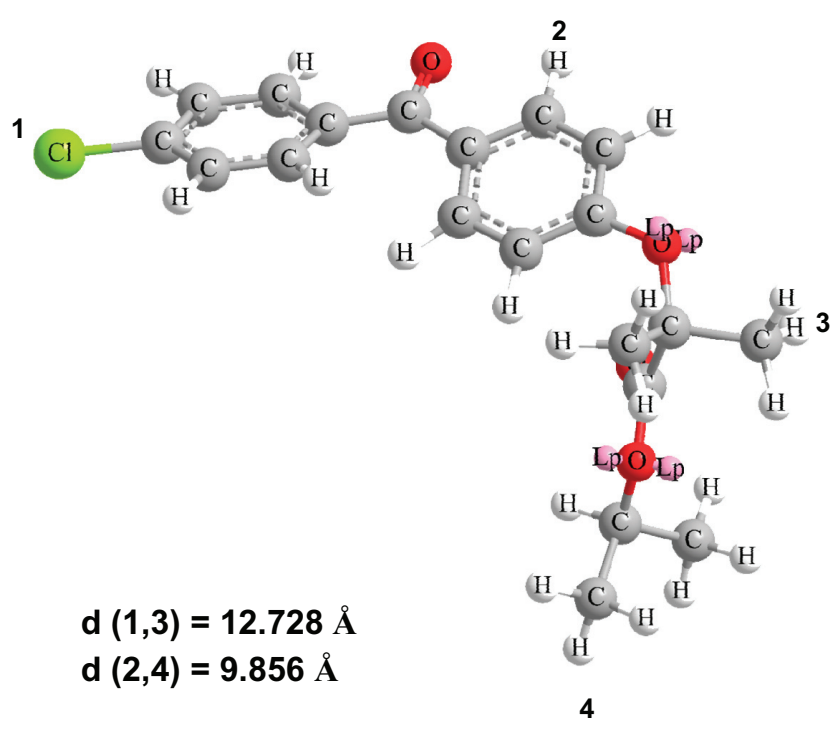

Figure 5 Three-dimensional fenofibrate molecule with corresponding interatomic distances. pore walls separate the fine amorphous particles perfectly and prevent recrystallization and crystal growth, even under severe storage conditions.

For comparison according to the adsorption method used, fenofibrate-loaded Neusilin UFL2 was also prepared by solvent evaporation and hot-melt adsorption at a fenofibrate to Neusilin UFL2 ratio of 40:60 (w/w). It was observed that when the fenofibrate-loaded Neusilin UFL2 was prepared using the supercritical method, neither the endothermic peak of differential scanning calorimetry nor the diffraction peaks of PXRD appeared (Table 3 and Figure 4). This is attributed to the high diffusivity, low viscosity, and noncohesive characteristics of the supercritical fluid. With the solvent evaporation method, introduction of fenofibrate into the pores of Neusilin UFL2 would be blocked due to low diffusivity, high velocity, and disturbance of wettability, as well as the surface tension of the organic solvent. ${ }^{28}$ Furthermore, crystalline fenofibrate formed on the adsorbent surface during solvent removal by slow evaporation. ${ }^{29}$ Similarly, with the hot-melt adsorption method, introduction of fenofibrate into the pores was also blocked due to the high viscosity of molten fenofibrate.

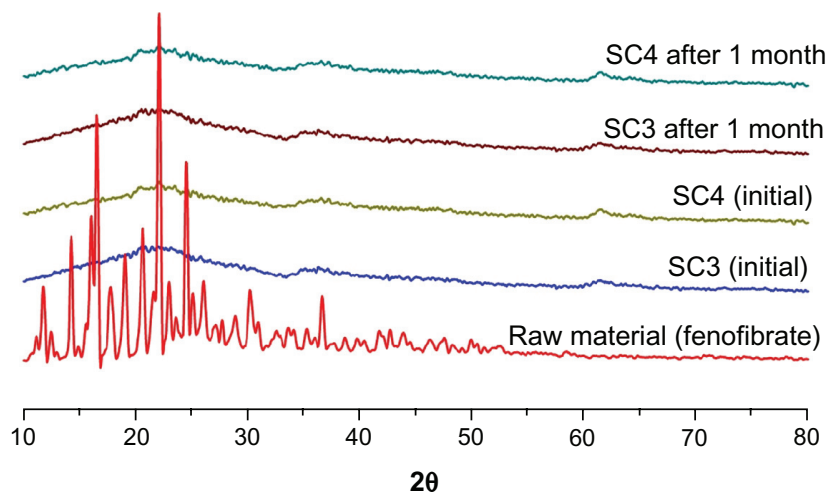

Figure 6 Powder X-ray diffraction patterns of prepared powders (SC3 and SC4) after storage at $40^{\circ} \mathrm{C}$ and $75 \%$ relative humidity.

Abbreviations: SC3, supercritical method 3 (Fenofibrate:Neusilin UFL2 $=40: 60$ ); SC4, supercritical method 4 (Fenofibrate:Neusilin UFL2 = 33:67). 
A

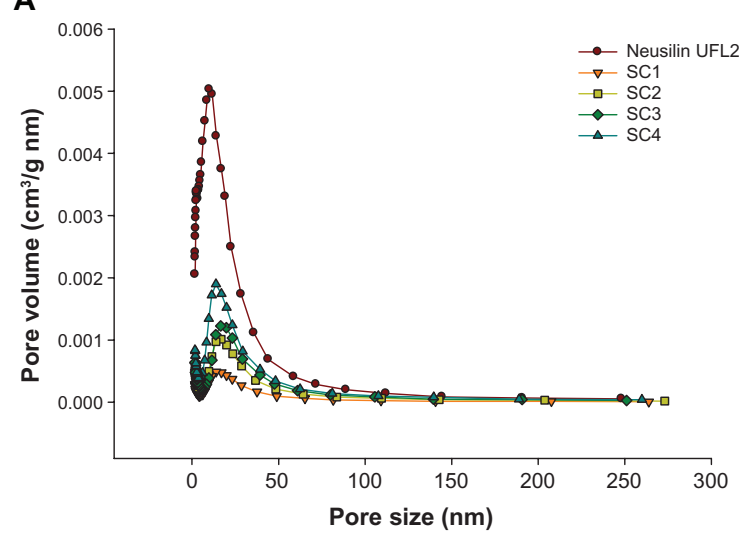

B

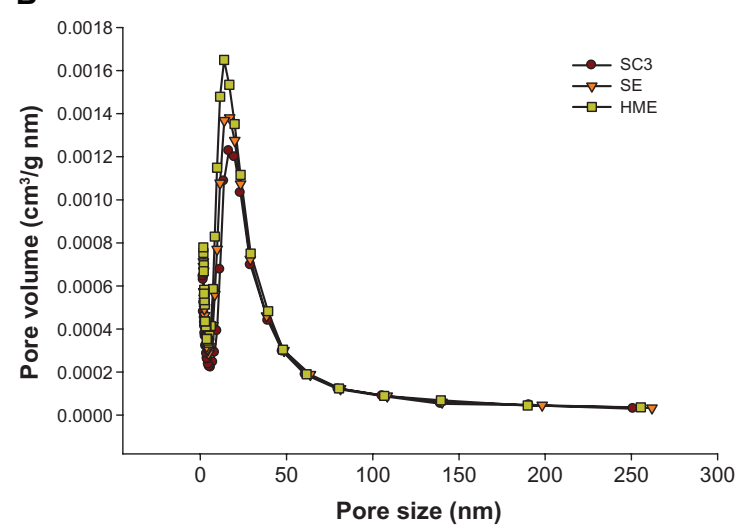

Figure 7 Pore size distribution related to the weight ratio of fenofibrate/Neusilin ${ }^{\circledR}$ UFL2 using the supercritical method (SC) (A) and the various processing methods (B). Abbreviations: HME, hot-melt adsorption method; SE, solvent evaporation method; SCI, supercritical method I (Fenofibrate:Neusilin UFL2 = 67:33); SC2, supercritical method 2 (Fenofibrate:Neusilin UFL2=50:50); SC3, supercritical method 3 (Fenofibrate:Neusilin UFL2 = 40:60); SC4, supercritical method 4 (Fenofibrate:Neusilin UFL2 = 33:67).

\section{Specific surface area and pore distribution analysis}

The results for specific surface area and total pore volume are shown in Table 3 and graphically represented in Figure 7. Raw Neusilin UFL2 had a very large specific surface area of $403.93 \pm 2.89 \mathrm{~m}^{2} / \mathrm{g}$. This large specific surface area and high adsorption capacity make Neusilin UFL2 a good core material for adsorption of many drugs. Both the specific surface area and total pore volume of Neusilin UFL2 decreased with an increasing fenofibrate to Neusilin UFL2 ratio. The Neusilin UFL2 pores were filled with fenofibrate, and both the specific surface area and total pore volume of the drugloaded Neusilin UFL2 decreased as the number of pores filled with fenofibrate increased.

Comparison of the different loading methods revealed that the specific surface area and total pore volume of fenofibrate-loaded Neusilin UFL2 decreased in the following order: hot-melt adsorption method $>$ solvent evaporation method $>$ supercritical method. This result is in agreement with differential scanning calorimetry and PXRD measurements. The supercritical fluid facilitated introduction of fenofibrate into the pores of Neusilin UFL2 and only the supercritical adsorption method resulted in complete pore filling.

\section{Morphology and elements on the surface}

An SEM photograph and the EDS patterns of raw fenofibrate, Neusilin UFL2, and powders prepared using the supercritical method are shown in Figure 8. The raw fenofibrate particles appear as irregular-shaped crystals with a broad size distribution, while the raw Neusilin UFL2 is a secondary agglomeration particle with a large specific surface area. In the EDS patterns of the raw fenofibrate (Figure 8A), the chloride peak of fenofibrate can be identified. In the case of raw Neusilin UFL2, the major elements identified were silicon, magnesium, and aluminum (Figure $8 \mathrm{~B}$ ). The SEM photograph and EDS patterns of the powders prepared using the supercritical method ( $\mathrm{SC} 3$, Figure $8 \mathrm{C}$ ) revealed no distinct difference in the surface morphologies of the raw Neusilin UFL2 and SC3. In addition, no fenofibrate crystals were observed. However, the EDS patterns of SC3 revealed small chloride peaks in addition to the large silicon, magnesium, and aluminum peaks, which indicate that the fenofibrate was adsorbed onto the pores of Neusilin UFL2.

\section{In vitro dissolution and in vivo study}

Powder dissolution profiles for the raw fenofibrate, commercial product (Lipidil Supra) which contains micronized fenofibrate, and powders prepared with different ratios of fenofibrate to Neusilin UFL2 using the supercritical method are shown in Figure 9. For the dissolution study of the commercial tablet, the tablet was ground in a mortar and suspended in dissolution medium. Dissolution of the fenofibrate adsorbed onto Neusilin UFL2 was higher than that for the raw fenofibrate. Among the powders prepared using the supercritical method, the dissolution rate of fenofibrate increased with decreasing crystalline fenofibrate values, and drug release from the SC3 and SC4 formulations with decreasing crystalline fenofibrate values of $0 \%$ was markedly enhanced. Within 5 minutes, approximately $80 \%$ of the drug dissolved for the prepared powders ( $\mathrm{SC} 3$ and SC4), compared with approximately $15 \%$ for the raw fenofibrate. 

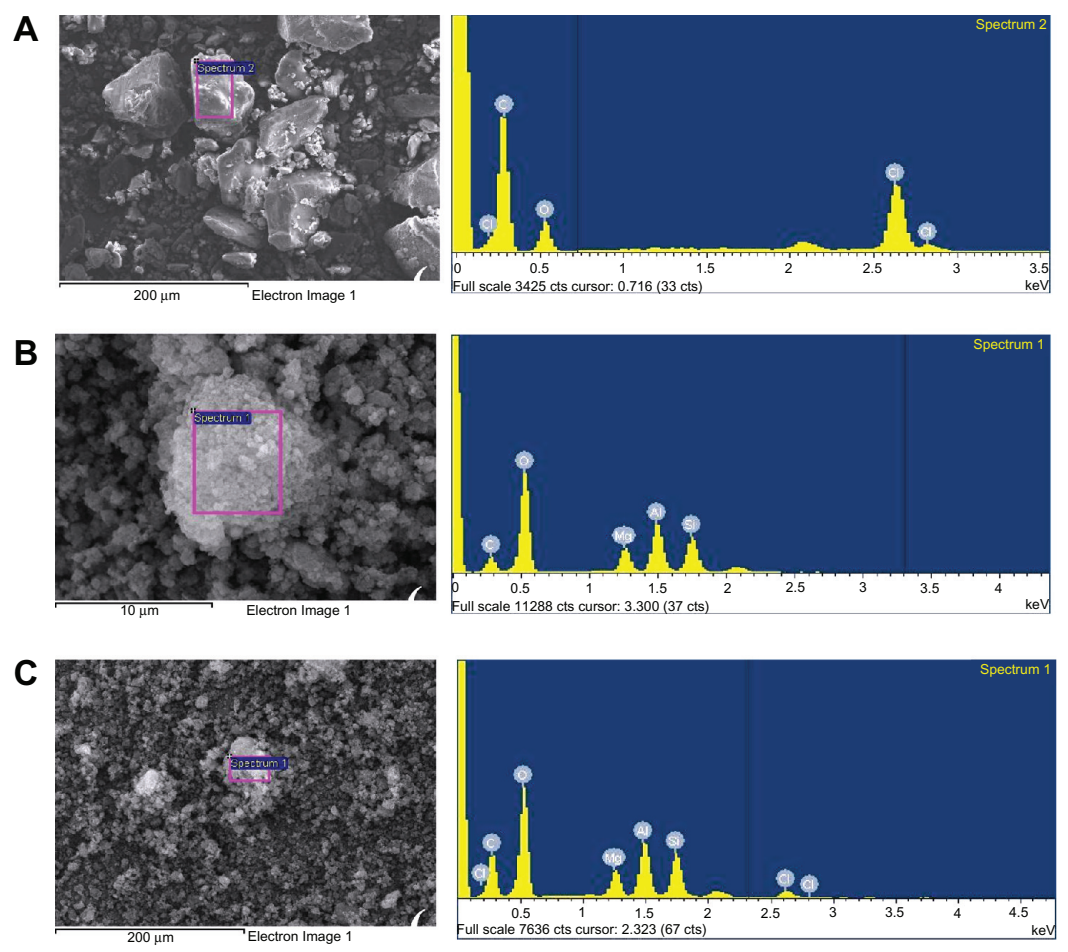

Figure 8 Scanning electron microscopy image and energy-dispersive spectrometry patterns of (A) raw fenofibrate, (B) raw Neusillin ${ }^{\circledR}$ UFL2, and (C) prepared powder (SC3).

Abbreviation: SC3, supercritical method 3 (fenofibrate:Neusilin UFL2 $=40: 60$ ).

The percent amount of drug dissolved after 10 and 30 minutes, dissolution efficiency at 60 minutes $\left(\mathrm{DE}_{60}\right)$, and relative dissolution rate at 10 minutes were calculated to compare the dissolution profiles for raw fenofibrate, the commercial product, and the powders prepared by various adsorption methods. Table 4 shows higher dissolution rates from the prepared powders than from raw fenofibrate and the commercial product. In particular, the $\mathrm{SC} 3$ formulation prepared using the supercritical method showed a faster dissolution rate than the raw fenofibrate and the commer- cial product, with approximately 1.89 -fold and 1.25 -fold increases in $\mathrm{DE}_{60}$, respectively. Based on the results of our studies, the faster dissolution rate of the drug from the SC3 formulation can be attributed to a decrease in particle size of fenofibrate after absorption of Neusilin UFL2, and a change from the crystalline to an amorphous form. ${ }^{30,31}$

The pharmacokinetic profiles after oral administration of raw fenofibrate, the commercial product, and $\mathrm{SC} 3$ in male Sprague Dawley rats are presented in Figure 10, and the pharmacokinetic parameters are summarized in Table 5.

Table 4 Dissolution efficiency at 60 minutes, percentage of drug dissolved at 10 and 30 minutes, and the relative dissolution rate from raw fenofibrate, the commercial product, and powders prepared using various adsorption methods

\begin{tabular}{llcc}
\hline Formulations & \% drug dissolved & & DE (60 minutes) \\
\cline { 2 - 4 } & I 0 minutes & 30 minutes & RDR (I O minutes) \\
\hline Unprocessed drug & $16.45 \pm 1.43$ & $53.78 \pm 1.35$ & $48.87 \pm 1.52$ \\
Commercial product & $38.72 \pm 6.57$ & $91.91 \pm 4.89$ & $73.90 \pm 5.19$ \\
Processed drug & & & 2.35 \\
SC3 & $94.29 \pm 1.78$ & $99.40 \pm 2.56$ & $92.28 \pm 1.49$ \\
Solvent evaporation method & $82.04 \pm 1.22$ & $93.98 \pm 2.87$ & $86.54 \pm 0.98$ \\
Hot-melt adsorption method & $77.96 \pm 1.38$ & $92.18 \pm 2.98$ & 8.98 \\
\hline
\end{tabular}

Note: Data are expressed as the mean \pm standard deviation $(n=6)$.

Abbreviations: DE, calculated from the area under the dissolution curve at 60 minutes and expressed as percentage of the area of the rectangle described by $100 \%$ dissolution in the same time; RDR, ratio between amount of drug dissolved from each formulation and that dissolved from unprocessed drug at 10 minutes; $\mathrm{SC}$, supercritical method 3 (fenofibrate:Neusilin UFL2 = 40:60). 

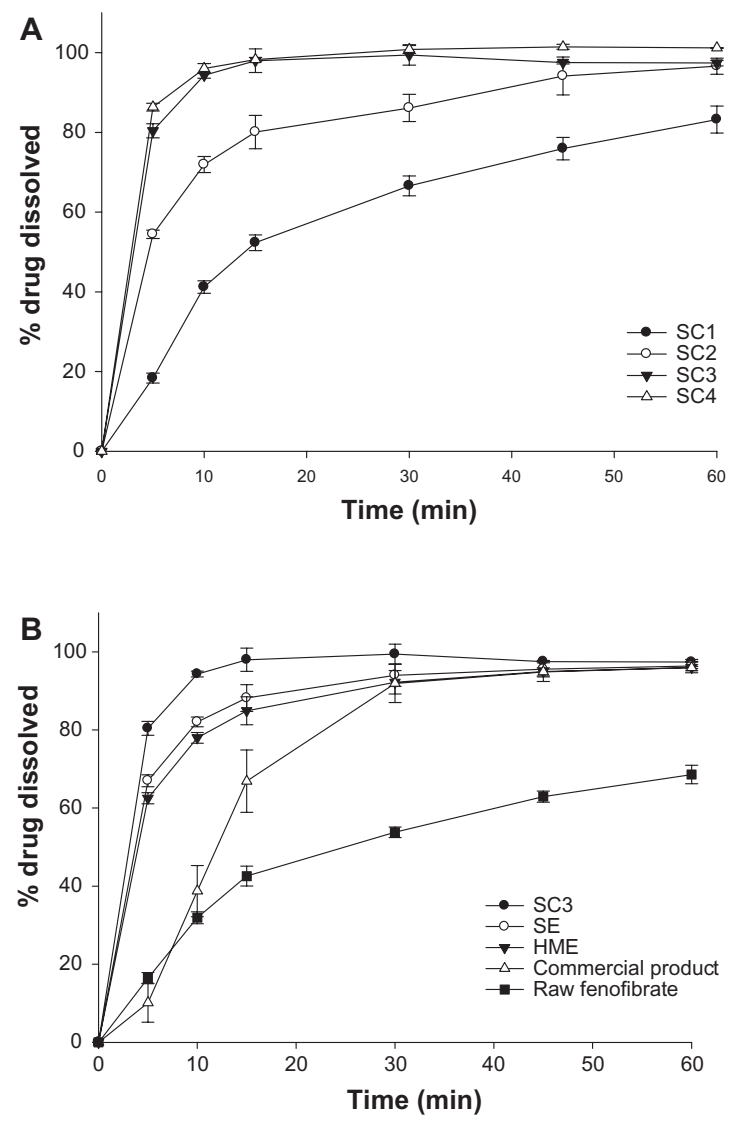

Figure 9 Dissolution profiles of raw fenofibrate, the commercial product (Lipidi Supra ${ }^{\circledR}$ ), and prepared powders in $0.025 \mathrm{M}$ sodium lauryl sulfate. Notes: (A) Dissolution profiles related to the weight ratio of fenofibrate/Neusilin UFL2 using supercritical method (SC). (B) Dissolution profiles from raw fenofibrate, the commercial product, and powders prepared using various adsorption methods. Data are expressed as the mean \pm standard deviation $(n=3)$.

Abbreviations: HME, hot-melt adsorption method; SE, solvent evaporation method; SCI, supercritical method I (Fenofibrate:Neusilin UFL2 = 67:33); SC2, supercritical method 2 (Fenofibrate:Neusilin UFL2 = 50:50); SC3, supercritical method 3 (Fenofibrate:Neusilin UFL2 = 40:60); SC4, supercritical method 4 (Fenofibrate:Neusilin UFL2 = 33:67).

The prepared powder (SC3) showed a significantly increased $\mathrm{AUC}_{0 \rightarrow 12 \mathrm{~h}}\left(4.62\right.$-fold) and $\mathrm{C}_{\text {max }}$ (4.52-fold) compared with raw fenofibrate $(P<0.05)$. Furthermore, the $\mathrm{AUC}_{0 \rightarrow 12 \mathrm{~h}}$ and $\mathrm{C}_{\max }$ of SC3 were comparable with those of the commercial product $(P>0.05)$. These results suggest that the

Table 5 Pharmacokinetic parameters after oral administration of fenofibrate to rats

\begin{tabular}{llll}
\hline & $\begin{array}{l}\mathbf{A U C}_{\mathbf{0} \rightarrow 12 \mathrm{~h}} \\
(\mu \mathrm{g} \mathrm{h} / \mathbf{m L})\end{array}$ & $\begin{array}{l}\mathbf{C}_{\max } \\
(\mu \mathrm{g} / \mathbf{m L})\end{array}$ & $\begin{array}{l}\mathbf{T}_{\max } \\
(\mathbf{h})\end{array}$ \\
\hline Raw fenofibrate & $144.46 \pm 61.57$ & $20.52 \pm 8.34$ & $3 \pm 0.82$ \\
$\begin{array}{l}\text { Commercial } \\
\text { product }\end{array}$ & $635.68 \pm 98.14$ & $89.60 \pm 12.02$ & $2.63 \pm 0.75$ \\
$\begin{array}{l}\text { Prepared } \\
\text { powder (SC3) }\end{array}$ & $667.90 \pm 106.29$ & $92.88 \pm 7.05$ & $3 \pm 0$ \\
\hline
\end{tabular}

Note: Data are expressed as mean \pm standard deviation $(n=5)$.

Abbreviations: $A \cup C$, area under the curve; $C_{\text {max }}$, maximal serum concentration; SC3, supercritical method 3 (fenofibrate:Neusilin UFL2 $=40: 60$ ); $T_{\text {max }}$, time to peak concentration.

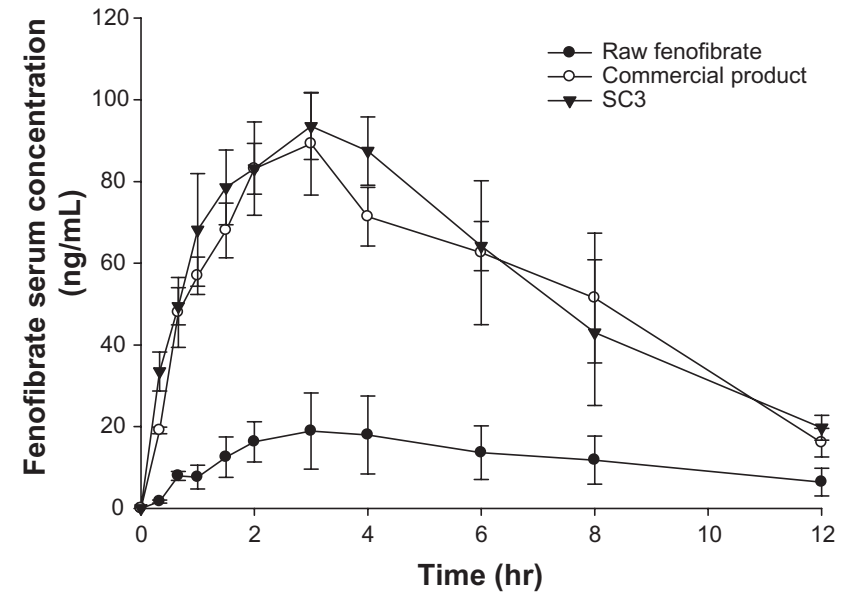

Figure 10 Serum concentration-time profile of fenofibrate in rats after oral administration of the raw fenofibrate, the commercial product (Lipidi Supra ${ }^{\circledR}$ ), and the prepared powder (SC3) at a dose equivalent to $50 \mathrm{mg}$ of fenofibrate $/ \mathrm{kg}$ of bodyweight. Note: Data are expressed as the mean \pm standard deviation $(n=5)$.

Abbreviation: SC3, supercritical method 3 (fenofibrate:Neusilin UFL2 = 40:60).

amorphous nature and small particle size of fenofibrate allows for apparently greater solubility, thereby increasing the dissolution rate and drug concentration available for absorption. ${ }^{32-34}$

\section{Conclusion}

In this study, an amorphous fenofibrate formulation was successfully prepared by melt adsorption using supercritical $\mathrm{CO}_{2}$. Fenofibrate adsorbed onto Neusilin UFL2 exists in an amorphous form and shows an enhanced dissolution rate and bioavailability. The enhancement in oral absorption of fenofibrate adsorbed onto Neusilin UFL2 was attributed to a higher dissolution rate as a result of the amorphous nature and reduction of particle size. This study demonstrates the usefulness of the supercritical method for improving the bioavailability of fenofibrate. Furthermore, the melt adsorption method using supercritical $\mathrm{CO}_{2}$ does not require organic solvents and can be used to improve the bioavailability of other poorly water-soluble drugs with low melting points.

\section{Acknowledgment}

This study was supported by a grant from the Korean Health Technology R\&D Project, Ministry for Health, Welfare and Family Affairs, Republic of Korea (A092018).

\section{Disclosure}

The authors report no conflicts of interest in this work.

\section{References}

1. Adkins JC, Faulds D. Micronised fenofibrate: a review of its pharmacodynamic properties and clinical efficacy in the management of dyslipidemia. Drugs. 1997;54:615-633. 
2. Murakami H, Murakami R, Kambe F, et al. Fenofibrate activates AMPK and increases eNOS phosphorylation in HUVEC. Biochem Biophy Res Commun. 2006;341:973-978.

3. Jinno J, Kamada N, Miyake M, et al. Effect of particle size reduction on dissolution and oral absorption of a poorly water-soluble drug, cilostazol, in beagle dogs. J Control Release. 2006;111:56-64.

4. Hancock BC, Zografi G. Characteristics and significance of the amorphous state in pharmaceutical systems. J Pharm Sci. 1997;86:1-12.

5. Van Nijlen T, Brennan K, Van den Mooter G, Blaton N, Kinget R, Augustijns P. Improvement of the dissolution rate of artemisinin by means of supercritical fluid technology and solid dispersions. Int $J$ Pharm. 2003;254:173-181.

6. Rasenack N, Mueller BW. Dissolution rate enhancement by in situ micronization of poorly water-soluble drugs. Pharm Res. 2002;19:1894-1900.

7. Kim M-S, Lee S, Park J-S, Woo J-S, Hwang S-J. Micronization of cilostazol using supercritical antisolvent (SAS) process: effect of process parameters. Powder Technol. 2007;177(2):64-70.

8. Heike F, Bernd F, Karl K, Roland B. Dissolution rate improvement of poorly water-soluble drugs obtained by adsorbing solutions of drugs in hydrophilic solvents onto high surface area carriers. Eur J Pharm Biopharm. 2006;62:171-177.

9. Sharma S, Sher P, Badve S, Pawar AP. Adsorption of meloxicam on porous calcium silicate: characterization and tablet formulation. AAPS Pharm Sci Tech. 2005;6:618-625.

10. Sher P, Ingavle G, Ponrathnam S, Pawar AP. Low density porous carrier: drug adsorption and release study by response surface methodology using different solvents. Int J Pharm. 2007;331:72-83.

11. Subramaniam B, Rajewski RA, Snavely K. Pharmaceutical processing with supercritical carbon dioxide. J Pharm Sci. 1997;86:885-890.

12. Jun SW, Kim M-S, Kim J-S, et al. Preparation and characterization of simvastatin/hydroxypropyl-[beta]-cyclodextrin inclusion complex using supercritical antisolvent (SAS) process. Eur J Pharm Biopharm. 2007;66:413-421.

13. Pasquali I, Bettini R, Giordano F. Solid-state chemistry and particle engineering with supercritical fluids in pharmaceutics. Eur J Pharm Biopharm. 2006;27:299-310.

14. Sanganwar GP, Gupta RB. Dissolution-rate enhancement of fenofibrate by adsorption onto silica using supercritical carbon dioxide. Int J Pharm. 2008;360:213-218.

15. Fischer K, Wilken M, Gmehling J. The effect of gas pressure on the melting behavior of compounds. Fluid Phase Equilib. 2003;210:199-214.

16. Gupta MK, Vanwert A, Bogner RH. Formation of physically stable amorphous drugs by milling with Neusilin. J Pharm Sci. 2003;92:536-551.

17. Gupta MK, Goldman D, Bogner RH. Enhanced drug dissolution and bulk properties of solid dispersions granulated with a surface adsorbent. Pharm Dev Technol. 2001;6:563-572.

18. Tandya A, Dehghani F, Foster NR. Micronization of cyclosporine using dense gas techniques. $J$ Supercrit Fluids. 2006;37:272-278.

19. Hussein K, Turk M, Wahl MA. Drug loading into [beta]-cyclodextrin granules using a supercritical fluid process for improved drug dissolution. Eur J Pharm Sci. 2008;33:306-312.
20. Dohrn R, Bertakis E, Behrend O, Voutsas E, Tassios D. Melting point depression by using supercritical $\mathrm{CO}_{2}$ for a novel melt dispersion micronization process. $J$ Mol Liq. 2007;131:53-59.

21. Strumendo M, Bertucco A, Elvassore N. Modeling of particle formation processes using gas saturated solution atomization, $J$ Supercrit Fluids. 2007;41:115-125.

22. Kerc J, Srcic S, Knez Z. Micronization of drugs using supercritical carbon dioxide. Int J Pharm. 1999;182:33-39.

23. Chen Y-M, Lin P-C, Tang M, Chen Y-P. Solid solubility of antilipemic agents and micronization of gemfibrozil in supercritical carbon dioxide. J Supercrit Fluids. 2010;52:175-182.

24. Heinz A, Gordon KC, McGoverin CM, Rades T, Strachan CJ Understanding the solid-state forms of fenofibrate - a spectroscopic and computational study. Eur J Pharm Biopharm. 2009;71:100-108.

25. Srinarong P, Faber JH, Visser MR, Hinrichs WLJ, Frijlink HW. Strongly enhanced dissolution rate of fenofibrate solid dispersion tablets by incorporation of superdisintegrants. Eur J Pharm Biopharm. 2009;73:154-161.

26. Sliwinska-Bartkowiak M, Dudziak G, Gras R, Sikorski R, Radhakrishnan R, Gubbins KE. Freezing behavior in porous glasses and MCM-41. Colloids Surf A Physicochem Eng Asp. 2001;187/188: 523-529.

27. Shen SC, Ng WK, Chia L, Dong YC, Tan RB. Stabilized amorphous state of ibuprofen by co-spray drying with mesoporous SBA-15 to enhance dissolution properties. J Pharm Sci. 2009;99:1997-2007.

28. Wakayama H, Goto Y, Fukushima Y. A novel method for tailoring porous structures of nanoporous materials using supercritical solvents. Phys Chem Chem Phys. 2003;5:3784-3788.

29. Charnay C, Bégu S, Tourné-Péteilh C, Nicole L, LernerDA, Devoisselle JM. Inclusion of ibuprofen in mesoporous templated silica: drug loading and release property. Eur J Pharm Biopharm. 2004;57:533-540.

30. Kim JS, Kim MS, Park HJ, Jin SJ, Lee S, Hwang SJ. Physicochemical properties and oral bioavailability of amorphous atorvastatin hemi-calcium using spray-drying and SAS process. Int J Pharm. 2008;359:211-219.

31. Kim MS, Jin SJ, Kim JS, et al. Preparation, characterization and in vivo evaluation of amorphous atorvastatin calcium nanoparticles using supercritical antisolvent (SAS) process. Eur J Pharm Biopharm. 2008;69:454-465.

32. Sugimoto M, Okagaki T, Narisawa S, Koida Y, Nakajima $\mathrm{K}$. Improvement of dissolution characteristics and bioavailability of poorly water-soluble drugs by novel cogrinding method using water-soluble polymer. Int J Pharm. 1998;160:11-19.

33. Yamashita K, Nakate T, Okimoto K, et al. Establishment of new preparation method for solid dispersion formulation of tacrolimus. Int J Pharm. 2003;267:79-91.

34. Vaughn JM, McConville JT, Crisp MT, Johnston KP, Williams RO. Supersaturation produces high bioavailability of amorphous danazol particles formed by evaporative precipitation into aqueous solution and spray freezing into liquid technologies. Drug Dev Ind Pharm. 2006;32:559-567.
International Journal of Nanomedicine

\section{Publish your work in this journal}

The International Journal of Nanomedicine is an international, peerreviewed journal focusing on the application of nanotechnology in diagnostics, therapeutics, and drug delivery systems throughout the biomedical field. This journal is indexed on PubMed Central, MedLine, CAS, SciSearch ${ }^{\circledR}$, Current Contents ${ }^{\circledR} /$ Clinical Medicine,

\section{Dovepress}

Journal Citation Reports/Science Edition, EMBase, Scopus and the Elsevier Bibliographic databases. The manuscript management system is completely online and includes a very quick and fair peer-review system, which is all easy to use. Visit http://www.dovepress.com/ testimonials.php to read real quotes from published authors. 